\title{
Queering International Law: possibilities, aliances, complicities and risks, de Dianne Otto
}

\author{
Book Review
}

Clarissa Brandão Kowarski ${ }^{1}$

A marginalização de países do Terceiro Mundo e a necessidade de democratizar o Direito Internacional considerando-se os interesses de povos e minorias excluídas do processo de construção normativa internacional ${ }^{2}$ são objeto tanto dos estudos feministas, como dos estudos sobre gênero e Direito Internacional e podem ser didaticamente agrupados no âmbito das TWAILs (Third World Approaches to International Law) (MICKELSON, 2008, p. 356$359)$.

Uma das tarefas dos autores integrantes das TWAILs ("Twail-ers") é buscar na genealogia dos institutos e teorias do Direito Internacional as interferências coloniais e imperialistas que silenciaram e reprimiram conceitos, histórias e conhecimentos subalternizados pela lógica moderna. As investigações descoloniais buscam caminhos de desconstrução da colonialidade por meio de "uma guinada epistêmica" que possibilite a emersão de outras epistemologias, outros princípios do conhecimento (MAGALHAES, 2013, p. 155-182).

No Brasil, George Galindo, em artigo publicado na Revista de Direito Internacional, trouxe a temática com explicações didáticas e metodológicas acerca da formação deste grupo de pesquisadores (GALINDO, 2013, p. 4668). Galindo elucida que a conferencia realizada na Faculdade de Direito de

\footnotetext{
${ }^{1}$ Doutora (2010) e Mestre (2005) pela Universidade do Estado do Rio de Janeiro - UERJ. Bacharel em Direito pela Universidade Federal do Rio de Janeiro - UFRJ (2001). Coordenadora e Professora permanente do Programa de Pós-Graduação em Direito Constitucional (PPGDC) na Faculdade de Direito da Universidade Federal Fluminense (UFF).

${ }^{2}$ Dois textos marcam a consolidação da agenda e o os objetos de pesquisa das TWAILS: CHIMNI, 2003, p. 47-73; e ANGHIE, 2003, p. 77-103.
} 
Harvard, em 1997, "New Approches to Third World Legal Studies” foi um marco para os "twail-ers". A partir deste evento, este grupo de pesquisadores e professores se organizaram para realização de outras conferências: TWAIL II, em 2001; TWAIL III, em 2007, TWAIL IV, em 2008 e TWAIL V, em 2012 (GATHII, 2011).

A despeito da realização das conferências e de outros eventos sobre TWAILs, Galindo sublinha a identificação de distintas ondas dentro do movimento. Apoiado nos textos de Anghie e Chimmi, Galindo entende que a TWAIL I tinha como foco de análise a atuação dos Estados colonizadores nos processos de descolonização e os efeitos dos mesmos nos Estados colonizados, enquanto processo contínuo de silenciamento destes em face daqueles. Neste contexto, "havia uma grande ênfase em princípios jurídicos como a igualdade soberana dos Estados e a não-intervenção, embora aqueles autores da primeira geração enxergassem que a independência política seria insuficiente para os Estados do terceiro mundo alcançarem a liberdade, em virtude da necessidade de rompimento de estruturas econômicas iníquas" (GALINDO, 2013, p. 48).

A TWAIL II, por sua vez, abandona a centralidade do Estado e busca explorar as violências perpetradas pelos mesmos Estados no âmbito póscolonial em face das minorias, tais como mulheres, trabalhadores e camponeses e ainda a permanência de efeitos do colonialismo sobre as antigas colônias por meio dos discursos civilizatórios que permeiam temas como "direitos humanos", "democracia" e "desenvolvimento" (GALINDO, 2013, p. 49).

Os contornos teóricos entre as duas gerações de TWAILs não são rígidos, uma vez que as preocupações com os efeitos da colonização sobre os países do terceiro mundo permanecem em ambas. E fala-se ainda em uma terceira geração (TWAIL III) na qual encontramos em Dianne Otto referência em seu artigo "The Gastronomics of TWAIL's Feminist Flavourings: Some Lunch Time Offerings" onde ela expõe suas angustias 
acerca de sua participação na $4^{\mathrm{a}}$. Conferência Mundial sobre a Mulher, em Beijing, 1995 e da interação entre as TWAILS e o feminismo. Neste artigo, Dianne Otto, importante autora "twail-er", parece se ressentir de não ter utilizado seu espaço para falar sobre TWAIL III e a importância do enlaçamento entre as pautas feministas e LGBTIs no âmbito do Direito Internacional.

Desde 2001, a professora Dianne Otto se dedica a estudar acerca das questões de gênero que envolvem o Direito Internacional. Inicialmente sob o enfoque feminista, a partir de palestra proferida no Annual Meeting of the American Society of International Law, em 2007, sobre o futuro do Direito Internacional, sob o título "Taking a break" from "normal": Thinking queer in the context of international law", a professora reorienta seu objeto de pesquisa a partir da teoria queer. ${ }^{3}$

O realinhamento dos estudos de Otto visa promover a interações entre as teorias críticas feministas sobre o direito internacional e a teoria queer. Seu alvo principal é provar que ambas teorias possuem como denominador comum o combate a heteronormatividade imperialista do Direito Internacional e os privilégios perpetuados no Direito Internacional pelo homem branco, heterossexual, cisgênero e ocidental. Ciente dos conflitos internos que permeiam os debates teóricos feministas, Otto propõe uma aliança entre ambos os grupos vulneráveis com o objetivo de promover uma releitura do Direito Internacional a partir da agenda LGTBI.

Sua obra aqui em análise, "Queering International Law: possibilities, aliances, complicities and risks", publicada em 2017, pela Editora Routledge, vem a complementar o trabalho da autora a partir do evento acadêmico realizado em Melbourne, em dezembro de 2015, no qual se apresentaram os co-autores da referida coletânea. Neste livro, Dianne busca

\footnotetext{
3 A teoria queer ainda não possui uma tradução reconhecida no Brasil, sendo que muitos autores optam por utilizá-la na sua forma original. Alguns autores nacionais utilizam o termo "estudos transviados" (BENTO, 2014). Sobre os conceitos da teoria queer, ver em BUTLER,, 1990; BUTLER, 1993; HAUSMAN, 1998; JIMÉNEZ, 2002; PRECIADO, 2002.
} 
a partir do conceito de curiosidade apresentar a teoria queer e seus impactos sobre o Direito Internacional. Ela explica o quê entende por 'queerificar'4 o direito internacional, enquanto proposta de projeto acadêmico e de militância inspirado na esperança de mudanças mais ambiciosas do que a mera inclusão normativa da pauta LGBTI (OTTO, 2017, p. 1). Para a autora, o termo "queer"5 assinala uma curiosidade acerca do fundamento conceitual e analítico do direito internacional "normal". A teoria queer aplicada ao direito internacional permitiria uma nova abordagem dos problemas jurídicos tradicionais enfrentados pela disciplina, bem como novas possibilidades de arranjos e soluções.

A teoria queer possibilita uma pausa das políticas de violações heteronormativas e oferece uma possibilidade de análise por meio do prazer, de celebrar a sexualidade humana e a expressão de gênero em toda a sua diversidade e fluidez para além das definições binárias sobre a heterossexualidade/homossexualidade e do feminino/masculino (OTTO, 2017, p. 1). A história da civilização como produto da repressão já foi bastante estudada pela escola de filósofos pós-modernos e permite compreender as estruturas de dominação estabelecida nas relações entre os indivíduos e também nas relações entre os Estados. A repressão, em especial, a sexual, permitiu o controle das instituições sobre os indivíduos e seus corpos e produziu o que Marcuse chamou de "mais-repressão", como a divisão de trabalho e o controle público da existência privada (MARCUSE, 1975).

A questão de gênero interpenetra o modo como diversos sistemas hierárquicos encontram-se estabelecidos e revelam formas e modelos

\footnotetext{
4 Todavia, a autora Dianne Otto promove derivações acerca do termo e por uma questão de coerência, buscamos manter a expressão "teoria queer" em todas as situações possíveis, todavia, neste momento, buscamos um neologismo com o objetivo de tentar expressar o conceito da ação proposta por Dianne Otto acerca da ideia "queering international law".

5 Para Fernandez (2017, p. 193-212) "queer" é um termo contestado e vai além das categorias identitárias de lésbicas, gays, bisexuais, transexuais e intersexas (e as identidades e práticas diversas de gênero e sexual não capturadas por esses termos). Queer é usado como uma ferramenta de crítica que oferece "resistência aos regimes do normal" e é simultaneamente "calibrado para explicar os antagonismos sociais da nação, raça, gênero, classe e sexualidade".
} 
biopolíticos $^{6}$ de estruturas de poder (OTTO, 2017, p. 1). As normas internacionais alicerçam o mainstream dos direitos relacionados ao gênero e rechaçam os conceitos fora do padrão tais como os islâmicos, os trabalhadores sexuais, os migrantes, as feministas e os ativistas de direitos de orientação sexual e de gênero (SOGI).

Sob esta perspectiva, Otto busca trazer para a discussão no âmbito do Direito Internacional algumas questões tais como: a) Como a discriminação e violência sofridas pela comunidade LGBTI devem ser tratadas sem que se implique na reafirmação do poder regulador do Estado Nação que apenas confere direitos por meio de seu enquadramento, tais como o casamento gay, na tentativa de domesticar os desejos dos indivíduos e impedir a radicalização das políticas queer?; b) Como seria possível buscar por meio dos direitos internacionais dos direitos humanos a valoração das vidas queer sem legitimar a herança imperial heteronormativa da estrutura da norma do Direito Internacional?; c) Como os ativistas podem atuar em redes par enfrentar os desafios das leis e práticas homofóbicas cometidas pelos Estados sem que a ideia do "homossexual" implique em uma nova categoria "civilização"?; d) Como as mudanças sociais e culturais advindas da comunidade LGBTI podem ser promovidas e aproveitadas sem que seja capturadas pelas econômicas neoliberais pinks as quais violam os ideais queer de redistribuição e igualdade econômica? (OTTO, 2017, p. 7)

Nesta perspectiva, Otto propõe uma divisão em sua obra que irá abordar cada uma das ideias descritas no título: "possibilidades", alianças", “cumplicidades" e "riscos" sejam elas enfrentadas pelos indivíduos queer, sejam pela própria teoria queer relacionando-os com temas caros ao Direito Internacional.

\footnotetext{
${ }^{6}$ A autora e grande parte da teoria queer constrói-se a partir dos estudos de Michel Foucault e de seus ensinamentos acerca da arqueologia e genealogia do poder/saber. "Ao relacionar o saber como exercício do poder, Foucault abre um leque para inúmeras digressões histórico-filosóficas que permeiam toda a sua obra. Foucault está preocupado em resolver problemas: analisa, exuma e desvenda seus objetos de estudo (loucura, psiquiatria, clínica médica, ciências humanas ou sexualidade)" (BRANDAO, 2017, p. 131-142). Neste sentido, Foucault busca desconstruir os conceitos pré estabelecidos, exumá-los e reconstruí-los a partir de uma perspectiva historicamente referenciada.
} 
Uma das abordagens propostas na obra é a questão do asilo queer. $\mathrm{O}$ controle da mobilidade humana através das fronteiras estaduais é uma das questões mais urgentes do ponto de vista político, do século XXI, enredadas como preocupação sobre o emprego, a economia, as ameaças à identidade nacional, o terrorismo e a segurança nacional. Em especial porque também cuidam dos limites e redesenhos do Estado-nação e da cidadania ${ }^{7}$ e, sob esta perspectiva, verificam-se avanços significativos das lutas LGBTI para o reconhecimento de gênero e sexualidade em casos de migração e busca de asilo. Todavia, apesar dos progressos, o reconhecimento das reivindicações de requerentes de asilo LGBTI ainda é um incômodo para muitos países (FERNANDEZ, 2017, p. 193-212). , lésbicas e gays continuaram enfrentando barreiras significativas à imigração nas próximas duas décadas, devido à incapacidade dos casais lésbicas e homossexuais de se casarem e por causa do não reconhecimento legal de suas famílias.

A Austrália e o Canadá foram os primeiros países a permitir a imigração dos parceiros do mesmo sexo dos nacionais no final da década de 1980. Hoje, cerca de 20 países reconhecem os direitos de imigração para casais binacionais de mesmo sexo, se um deles é um cidadão (FERNANDEZ, 2017, p. 193-212).

Fernandez explica que a Convenção da ONU de 1951 sobre o Estatuto dos Refugiados ("Convenção sobre Refugiados") não incluiu explicitamente a proteção ao grupo LGBTI, limitando-se a definir o refugiado como "uma pessoa que está fora do seu país de cidadania porque tem motivos fundados para o medo da perseguição por causa de sua raça, religião, nacionalidade, associação de um grupo social particular ou de uma opinião política, e é incapaz de obter um lugar seguro de seu país de origem ou, devido a esse

\footnotetext{
${ }^{7}$ A autora restringe a sua análise aos migrantes, requerentes de asilo e refugiados, embora existam outras categorias de fronteiras (migrantes econômicos, migrantes familiares ou parceiros, viajantes empresariais e turistas) que têm limites confusos que se sobrepõem e que devem ser reconhecidas como contingentes na existência anterior de nações e fronteiras. (OTTO, 2017, p. 212).
} 
medo, não está disposto a aproveitar a proteção desse país" (FERNANDEZ, 2017, p. 193-212).

Em razão deste silêncio, os pedidos de refúgio para lésbicas e gays foram rotineiramente negados até que a Holanda se tornou a primeira nação do Norte a reconhecer a orientação sexual como motivo de proteção de perseguição, seguidos pelos Estados Unidos (em 1990) e Canadá (em uma decisão de 1991 do Supremo Tribunal de Justiça (AG) / Ward e outros países como Austrália e Reino Unido). Já na década de 1990, organizações internacionais de direitos humanos, como a Anistia Internacional e a Human Rights Watch passaram a defender que a proteção contra a perseguição homossexual e baseada no gênero era de competência do direito internacional dos refugiados, iniciando-se um extensivo levantamento e documentação de perseguições com base no gênero e orientação sexual em todo o mundo (FERNANDEZ, 2017, p. 193-212).

Este material serviu para a elaboração das "Diretrizes do Alto Comissariado das Nações Unidas para Refugiados (ACNUR) sobre proteção internacional: perseguição relacionada ao gênero em 2002”, que reconheceu explicitamente que a orientação sexual deve ser considerada como "pertencimento a um grupo social particular" e, portanto, um fundamento relevante em pedidos de proteção contra a perseguição sob a Convenção dos Refugiados (FERNANDEZ, 2017, p. 193-212).

Outra questão tratada na obra é a inserção da proteção LGBTI na pauta da ONU. Em 2010, a Assembleia Geral da ONU adotou a primeira resolução sobre direitos LGBTs, que exigia o fim das mortes de pessoas em função da sua orientação sexual (GROSS, 2017, p. 158-164). Em 2011, por uma margem apertada, o Conselho de Direitos Humanos, que expressava grave preocupação sobre os atos de violência praticados contra indivíduos em função de sua orientação sexual e identidade de gênero. E em 2016, o Conselho de Direitos Humanos decidiu nomear um especialista para cuidar 
da proteção contra a violência e discriminação pautada em orientação sexual e identidade de gênero.

Diversos Estados se sentiram afrontados, como, por exemplo, a Organização da Cooperação Islâmica que propôs uma série de objeções e emendas sob a alegação de que a ONU estaria impondo determinado posicionamento violando questões de soberania em nome de proteção dos direitos humanos. Segundo Aeyal Gross, "no que poderia ser chamado de nacionalismo homofóbico, os Estados vestem sua homofobia como oposição global do Sul à condicionalidade, negação da diferença cultural e pisoteamento da soberania". 8

Outro exemplo explorado no livro por Anneken Sørlie é a reinvindicação dos direitos de pessoas trangêneras perante o Tribunal Europeu dos Direitos do Homem (TEDH) que reconheceu o gênero como categoria social, porém ainda remanescendo o aspecto biológico e sua interface com a questão da parentalidade (SØRLIE, 2017, p. 171-190). A maioria das reclamações foi julgada como uma questão de direito ao respeito pela vida privada de acordo com o artigo $8^{\circ}$ da Convenção Europeia de Direitos Humanos (CEDH) que apenas protege as pessoas contra interferências arbitrárias na sua vida privada ou familiar por parte das autoridades públicas, embora coloque obrigações positivas aos Estados para garantir que o direito de todos à vida privada seja respeitado.

A identidade de gênero se enquadra nos termos do artigo 14 da $\mathrm{CEDH}$ que proíbe a discriminação no gozo de todos os direitos e liberdades. De acordo com o TEDH, o respeito pela dignidade humana e a liberdade humana constituem a própria essência da CEDH e a noção de autonomia pessoal é um princípio importante na interpretação do artigo $8^{\circ}$. O direito ao respeito pela vida privada abrange a integridade pessoal de uma pessoa e também questões como identidade pessoal e desenvolvimento pessoal.

\footnotetext{
8 "In what could be termed homophobic-nationalism, states are here participating in whitewashing dressing up their homophobia as global South opposition to conditionality, denial of cultural difference and trampling of sovereignty" (GROSS, 2017, p. 161).
} 
Estados partes têm a obrigação positiva de tomar medidas para garantir que as pessoas transgêneras possam viver de acordo com sua identidade de gênero, alterando documentos de identidade quanto ao gênero. Porém, as obrigações dos Estados, além da simples questão de corrigir o gênero entendido como binário, não foram esclarecidas explicitamente.

Sørlie defende a ideia de adoção de categorias parentais neutras de gênero de acordo com a lei, argumentando que os termos neutros em termos de gênero poderiam incluir e refletir melhor a realidade dos pais que vivem na Noruega contemporânea e em muitas outras partes do mundo (SØRLIE, 2017, p. 171-190). A paternidade neutra em termos de gênero também ajudaria a concretizar os princípios dos direitos humanos de autoidentificação, integridade pessoal e autonomia que estão subjacentes a novas leis relacionadas à mudança de gênero legal.

Para Otto, a teoria queer expande o projeto feminista ${ }^{9}$ à medida que denuncia a demonização de todas as minorias sexuais e de gênero incluindo as mulheres. Para tanto, a inserção da teoria queer nas teorias críticas do Direito Internacional, contribuem para "repensar a história do Direito Internacional contemporâneo e entender que existem outros direitos internacionais que precisamos reconhecer ou criar para gerar um mundo mais justo" (ESLAVA; OBREGON; URUEÑA, 2016, p. 17).

A ideia de "vivermos um Direito sonâmbulo" (BRANDAO; NUNES, 2017, p. 321), teleguiado pelas estruturas imperiais e colonizadoras de um Direito Internacional hegemônico, europeizante e heteronormativo é o ponto de embate das teorias críticas do Direito Internacional, com destaque para as análises promovidas pelas teorias feminista e queer. A epistemologia imperialista e colonizadora se perpetua até os presentes dias modelando as relações sociais, econômicas e políticas e o Direito Internacional possui um

\footnotetext{
${ }^{9}$ Otto evidencia que sua obra e os trabalhos dos coautores não pretendem defender a autonomia da teoria queer, tampouco suplantar as teorias feministas. A correlação entre ambas reside na forte tradição feminista de apoio a liberdade sexual, motivo pelo qual a coexistência de ambas, ainda que nem sempre fácil, resida no combate a violência e a exploração sexual.
} 
relevante papel neste contexto, pois "serve ao mesmo tempo como linguagem do imperialismo e como linguagem para resisti-lo" (ESLAVA; OBREGON; URUEÑA, 2016, p. 93).

A proposta de Dianne Otto é elaborar novas questões sob a ótica queer buscando soluções que ao invés de ameaçar, contribua para proliferar práticas emancipatórias de liberdade e prazer não apenas de orientação sexual, mas também sobre raça, classe, gênero e outros indutores de poder, contribuindo para modificar o paradigma do Direito Internacional (OTTO, 2017, p. 11).

\section{Referências}

ANGHIE, Antony; CHIMNI, B. S. Third world approaches to international law and individual responsibility in internal conflicts. Chinese Journal of International Law. Beijing. Vol. 2. $\mathrm{N}^{\mathrm{o}}$ 1, 2003, p. 77-103.

BENTO, Berenice. O que pode uma teoria? Estudos transviados e a despatologização das identidades trans. Florestan, n. 2, p. 46, 2014

BRANDAO, Clarissa; NUNES, Bárbara. Direito Internacional Antropofágico: contribuições de Oswald de Andrade e Balakrishnan Rajagopal. Anais V CIDIL, v.1 (2017), p. 321. Disponível em: http://seer.rdl.org.br/index.php/anacidil/article/view/273/pdf. Acesso em: 14 mai. 2019.

BRANDAO, Clarissa. Revisitando o debate Habermas Foucault. In: GURGEL, Claudia, MELLO, Cleyson, GUERRA, Sonia. (Org.). Dignidade, Direito e Filosofia: estudos em homenagem a Andre R. C. Fontes. Juiz de Fora: Editora Editar, 2017, v. 1, p. 131-142)

BUTLER, Judith P. Gender trouble: feminism and the subversion of identity. New York: Routledge, Chapman \& Hall, 1990.

BUTLER, Judith. Bodies that matter: on the discursive limits of "sex". New York: Roudedge, 1993.

CHIMNI, B. S. Third World Approaches to International Law: A Manifesto. In: ANGHIE, Antony; CHIMNI, Bhupinder; MICKELSON, Karin and OKAFOR, Obiora. The Third World and International Order: Law, Politics and Globalization. Leiden: Martinus Nijhoff, 2003.

ESLAVA, Luis, OBREGON, Liliana; URUEÑA, René. Imperialismo(s) y derecho(s) internacional(es): ayer y hoy. In: ANGHIE, A., ORFORD, A, KOSKENNIEMI, M. Imperialismo y derecho internacional: historia y legado. Bogotá, Siglo del Hombre Editores, 2016.

FERNANDEZ, Bina. Queer border crossers: pragmatic complicities, indiscretions and subversions. In: OTTO, Dianne (org). Queering International Law: possibilities, alliances, complicities and risks. NY: Routledge, 2017, p 193-212. 
GALINDO, George Rodrigo Bandeira. A volta do terceiro mundo ao direito internacional. Boletim da Sociedade Brasileira de Direito Internacional, Brasília, v. 119-24, p. 4668, 2013.

GATHII, James T. TWAIL: A Brief History of Its Origins, Its Decentralized Network, and a Tentative Bibliography, 3 Trade L. \& Dev. 26 (2011).

GROSS, Aeyal. Homoglobalism: the emergence of global gay governance. In OTTO, Dianne (org). Queering International Law: possibilities, aliances, complicities and risks. NY: Routledge, 2017, pp. 158-164.

HAUSMAN, Bernice L. Sex Before Gender: Charlotte Perkins Gilman and the Evolutionary Paradigm of Utopia. Feminist Studies, vol. 24. ed. 3. 1998.

JIMÉNEZ, Rafael M. Mérida. (org.) Sexualidades transgresoras: una antología de estudios queer. Barcelona: Icaria, 2002.

MAGALHAES, José Luiz Quadros de; AFONSO, Henrique Weil. Para contar as outras estórias: direito internacional e resistência contra hegemônica no Terceiro Mundo, Rev. Fac. Dir Sul de Minas, 29(1), 2013, p. 155-182.

MARCUSE, Hebert. Eros e a civilização. Rio de Janeiro: Zahar, 1975, 5ª Ed.

MICKELSON, Karin. Taking stock of TWAIL histories. International Community Law Review. The Hague. Vol. 10. No 4, 2008, p. 356-359.

OTTO, Dianne (org). Queering International Law: possibilities, aliances, complicities and risks. NY: Routledge, 2017.

PRECIADO, Beatriz. Manifiesto Contrasexual. Barcelona, Editorial Anagrama, 2002.

SØRLIE, Anniken. Governing (trans)parenthood: the tenacious hold of biological connection and heterosexuality. In: OTTO, Dianne (org). Queering International Law: possibilities, alliances, complicities and risks. NY: Routledge, 2017, pp. 171-190.

Artigo recebido em: 08/05/2019.

Aceito para publicação em: 20/05/2019. 